\title{
Het bepalen van de tolerantie in de jaarrekening
}

\section{Drs. J. A. Emanuels en Drs. Ph. Wallage}

\section{Inleiding en begripsbepaling}

Een jaarrekening moet volgens de Nederlandse wet aan een aantal eisen voldoen. De belangrijkste eis wordt genoemd in artikel 362, lid 1 Boek 2 titel 9 van het Burgerlijk Wetboek. Hier wordt gesteld dat de jaarrekening voldoende inzicht in het vermogen en de resultaten van de rechtspersoon moet verschaffen. Voldoende inzicht in de werkelijke situatie kan alleen worden verkregen als de jaarrekening geen fouten en/of omissies van materiële betekenis bevat.

Van materiële betekenis zijn die fouten en/of omissies in de jaarrekening, waarvan het individuele of gezamenlijke effect van zodanige betekenis wordt geacht, dat in de gegeven omstandigheden moet worden verondersteld, dat de oordeelsvorming van de modale gebruiker van de jaarrekening zal worden beïnvloed of gewijzigd.

Genoemd materialiteitsbegrip staat de laatste tijd sterk in de belangstelling in de Nederlandse literatuur. $Z o$ verscheen in dit blad een artikel met de titel 'De betekenis van "materiality" voor de accountantscontrole', van de hand van J. F. van Dijk RA. Deze auteur had ook een belangrijk aandeel in NIvRA-geschrift nr. 46 (februari 1989) over dit onderwerp. In dit artikel zullen wij de term tolerantie gebruiken in plaats van 'materiality' of 'materialiteit'.

In de Verenigde Staten is reeds in de jaren zeventig een aanzet gegeven tot het ontwikkelen van een theoretisch onderbouwde en praktisch hanteerbare, benadering van het begrip tolerantie. Een pionier op dit gebied is R. K. Elliott, die onder andere met enkele artikelen (Journal of Accountancy, juli 1972 en maart 1983) belangrijk werk verrichtte.

Inmiddels zijn er in de Verenigde Staten enige
'Statements on Auditing Standards' (SAS 39 en SAS 47) verschenen, die implementatie beogen van een op tolerantie en accountantscontrolerisico gebaseerde controle-aanpak. Doelstelling van deze, voor accountants dwingende, voorschriften is het verhogen van de effectiviteit van de controle.

Zoals reeds gesteld heeft tolerantie betrekking op de nauwkeurigheid waarmee de jaarrekening de werkelijkheid weergeeft. Het accountantscontrolerisico is het risico dat zich na accountantscontrole een niet ontdekte, materiële fout en of omissie in de jaarrekening bevindt (het is dus de kwade kans dat er ten onrechte een goedkeurende verklaring wordt afgegeven).

De begrippen tolerantie en accountantscontrolerisico bepalen gezamenlijk de door de accountant te leveren controle-inspanning. In figuur 1 geven

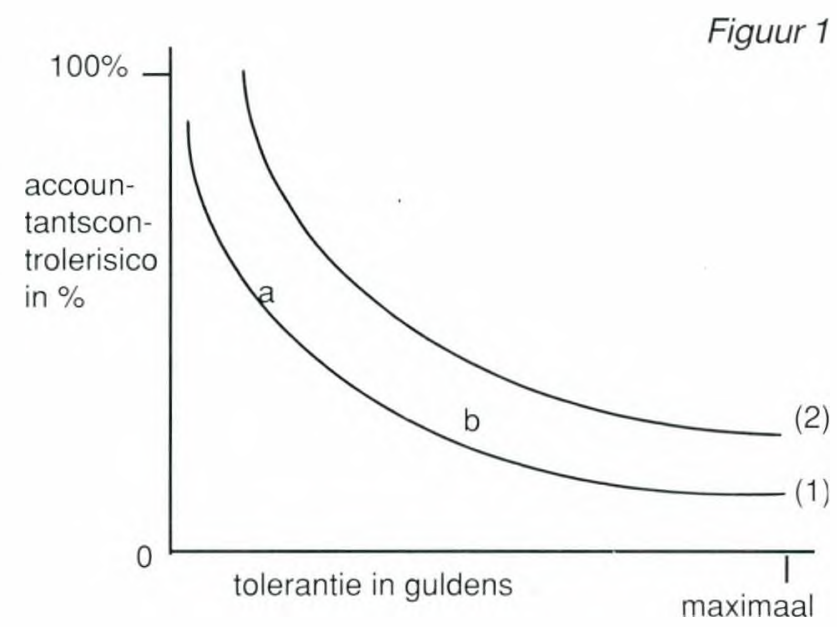

Drs. J. A. Emanuels en Drs. P. H. Wallage, registeraccountants, studeerden bedrijfseconomie aan respectievelijk de universiteiten van Groningen en Amsterdam. Beide werkzaam bij de maatschap Deloitte Dijker Van Dien. 


\section{MAB}

de lijnen 1 en 2 een verschillend niveau van controle-inspanning weer. De punten op lijn 1, respectievelijk lijn 2, illustreren echter een gelijk niveau van controle-inspanning, bij verschillende combinaties van tolerantie en accountantscontrole-risico (D. A. Leslie, 1985, p. 162).

Vergelijken wij lijn (1) met lijn (2) dan blijkt hieruit dat de controle-inspanning die door het niveau van lijn (1) wordt weergegeven hoger is. Dit betekent dat het risico dat ten onrechte een goedkeurende verklaring wordt gegeven op lijn (1) lager is dan op lijn (2), gegeven een zelfde tolerantie.

Op lijn (1) bestaat in punt b een kleinere kans op een materiële fout dan in punt $a$, doch daarentegen zijn de fouten in punt $b$ minder snel materieel. Bij een zelfde controle-inspanning (lijn 1) wordt op deze wijze het substitutie-effect tussen tolerantie en het accountantscontrole-risico weergegeven. Nader onderzoek zal moeten uitwijzen of, en in hoeverre, dit substitutie-effect in de accountantscontrole daadwerkelijk waargenomen kan worden.

In dit artikel zullen wij ons verder richten op de wijze waarop de tolerantie in de jaarrekening bepaald kan worden. Wij kunnen op basis van eigen waarneming stellen dat in de Nederlandse accountantspraktijk, onder invloed van de geschetste ontwikkeling in de Verenigde Staten enige methodieken voor het bepalen van de tolerantie zijn geïntroduceerd. Deze methodieken bestaan grotendeels uit relatief simpele vuistregels. In paragraaf 3 zal hier nader op worden ingegaan, nadat in paragraaf 2 is aangegeven wat het mogelijke belang van een dergelijke methodiek is. Voor zover ons bekend heeft in Nederland nog geen onderzoek plaatsgevonden naar de toepasbaarheid en de aanvaardbaarheid van deze methodieken. Daarom is door de auteurs gedurende 1988 onderzoek verricht naar de mogelijkheid om een genuanceerde methodiek voor het bepalen van de tolerantie in de controle van jaarrekeningen te ontwerpen. Bij de opzet van dit onderzoek bleek het om praktische redenen moeilijk te zijn om gebruikers van jaarrekeningen direct te benaderen met het verzoek aan te geven wat door hen als aanvaardbare tolerantie in de betreffende jaarrekening wordt ervaren. De voor- naamste reden hiervan is dat de groep gebruikers per onderneming sterk kan verschillen.

Als alternatief is door ons gekozen voor het benaderen van accountants, omdat deze om hun functie te kunnen vervullen op de hoogte moeten zijn van de verwachtingen van de gebruikers van door hen gecontroleerde jaarrekeningen. Deze verwachtingen omvatten onder andere de mate van nauwkeurigheid waarmee de in de jaarrekening gepresenteerde cijfers de realiteit weergeven.

In paragraaf 4 van dit artikel gaan wij in op de methode en de uitkomsten van het door ons uitgevoerde onderzoek. Vervolgens zullen in de paragrafen 5 en 6 enkele bijzondere aspecten van het tolerantiebegrip worden besproken. In paragraaf 7 worden tenslotte enkele afsluitende opmerkingen gemaakt.

\section{Het belang van een uniforme methodiek}

Het belang van een uniforme methodiek voor het bepalen van de tolerantie is tweeledig:

- enerzijds worden de gecontroleerde en de gebruiker van de jaarrekening niet geconfronteerd met wisselende maatstaven ter bepaling van de tolerantie. Men wordt hierdoor beter in staat gesteld de betekenis van de in de verklaring gebezigde term 'getrouw beeld' te interpreteren. Als maatstaf kunnen bijvoorbeeld de omvang van de onderneming, het resultaat of de financieringsstructuur worden gehanteerd;

- anderzijds kan een eenduidige methodiek een gestructureerd oordeelsvormingsproces van de accountant bevorderen (zie ook Ph. Wallage, 1989). Hiermee samenhangend wordt een instrument verkregen om controles gerichter uit te voeren, hetgeen efficiencyverhogend kan werken.

Tegen het ontwikkelen van een dergelijke uniforme methodiek kan naar onze mening worden ingebracht, dat de accountant minder ruimte wordt gelaten om specifieke omstandigheden in het oordeelsvormingsproces te betrekken.

Om deze reden dient een dergelijke eenduidige methodiek ook op systematische wijze met bijzondere, mogelijkerwijs niet te kwantificeren, omstandigheden rekening te houden. 


\section{MAB}

Zo zijn onder andere de volgende bijzondere omstandigheden te onderkennen:

- de wens van de opdrachtgever om een lager tolerantiebedrag te hanteren;

- nauwkeurigheidsvereisten van specifieke gebruikersgroepen;

- overheidsvoorschriften;

- niet gecorrigeerde, niet materiële fouten in voorafgaande jaarrekeningen waarmee in dit jaar rekening dient te worden gehouden.

\section{Ontwikkelde methodieken}

Naar onze mening moet een methodiek voor het bepalen van de tolerantie:

a afhankelijk zijn van de omvang van de onderneming. De nauwkeurigheid van de jaarrekening kan absoluut gezien afnemen naarmate de onderneming groter wordt. Bij een grote onderneming heeft een geringe fout of omissie geen invloed op het getrouwe beeld van de jaarrekening, terwijl dit bij een kleine onderneming wel het geval kan zijn. Omdat de tolerantie in principe een weerslag vormt van de omvang van de bedrijfsactiviteiten, en deze in het algemeen aan weinig variatie onderhevig is, leidt een dergelijke methodiek tot stabiele tolerantiebedragen in de tijd;

b rekening houden met bijzondere omstandigheden (zie paragraaf 2);

$c$ eenvoudig toepasbaar zijn;

d rekening houden met de aard van de huishouding. Zo kan bij een non-profit organisatie het resultaat niet als criterium voor de tolerantie worden gehanteerd.

Het hanteren van een vaste methodiek op grond waarvan de tolerantie wordt bepaald, was tot voor kort in de Nederlandse controlepraktijk niet gebruikelijk. Ook in het onlangs verschenen NIVRA-geschrift wordt geen voorkeur uitgesproken voor een bepaalde, eenduidige methodiek. Uit de literatuur en de in Canada en de Verenigde Staten gevoerde discussies, kunnen de volgende kwantitatieve methodieken (Leslie) worden onderkend:

\section{5 a 10\% van de nettowinst voor belastingen}

Vijf procent voor relatief grote winsten en tien pro- cent voor relatief kleine winsten. In plaats van de nettowinst kan de genormaliseerde winst worden gehanteerd.

Het genormaliseerde resultaat kan bijvoorbeeld worden bepaald door een normpercentage (bijvoorbeeld een gemiddeld branche-rendement of het promesse-disconto) van het eigen of werkzaam vermogen te nemen.

\section{2 brutowinst}

De brutowinst kan worden gedefinieerd als de omzet minus de variabele kosten van de verkopen (contributiemarge).

Met behulp van tabel 1 kan de tolerantie worden bepaald.

Tabel 1: Tolerantie als percentage van de brutowinst

\begin{tabular}{lll}
\hline Brutowinst range $(f)$ & Percentage van de brutowinst \\
\hline 0 & -20.000 & 5 à $2 \%$ \\
20.000 & -1.000 .000 & 2 à $1 \%$ \\
$1.000 .000-100.000 .000$ & 1 à $0.5 \%$ \\
$100.000 .000-1$ miljard & 0.5 \\
meer & 0.5 à $0.1 \%$ \\
\hline
\end{tabular}

\section{$31 \%$ van het eigen vermogen}

$40.5 \%$ van de omzet

5 rekenkundig gemiddelde van methodiek 1 tot en met 4

6 een variabel percentage van de omzet of van het activa-totaal

Met betrekking tot deze methodiek is de volgende formule (in guldens) door ons afgeleid uit de resultaten van een door Elliott intern uitgevoerd onderzoek bij Peat Marwick Mitchell en Co. (Carmichael en Benis, 1988).

\section{7} $(1 / 2.2)^{(1 / 3)}$ * (omzet of activa-totaal)

(waarbij $1 \$=f 2,20$ ) 


\section{MAB}

Voor zover het activa-totaal groter is dan de omzet, wordt het activa-totaal gebruikt.

In het vervolg van deze paragraaf zetten wij bovenstaande methodieken af tegen de eerder genoemde criteria.

\section{a Mate waarin rekening wordt gehouden met de} omvang van de onderneming

De tolerantie wordt bij de methodieken 2, 3, 4 en 6 en in mindere mate bij methodiek 5 bepaald door de omvang van de onderneming. Bij de methodieken 3,4 , en 5 varieert de tolerantie in guldens recht evenredig met de grootte van de onderneming. Stel bijvoorbeeld dat het eigen vermogen met een factor 2 wordt vergroot, dan is het gevolg van het toepassen van methodiek 3 , dat de tolerantie eveneens verdubbeld.

Bij methodiek 6 neemt de tolerantie relatief minder sterk toe (niet lineair) dan de stijging van de omzet respectievelijk activa-totaal. Er bestaat met andere woorden 'een bovengrens' voor de hoogte van het tolerantiebedrag. Methodiek 1 leidt tot een tolerantiebedrag dat niet direct gekoppeld is aan de omvang van de organisatie. Zo zou in het theoretische geval het tolerantiebedrag van een grote doch laag renderende multinational, gelijk kunnen zijn aan dat van een goed renderende plaatselijke supermarkt.

In principe leiden de methodieken 3, 4, 5 en 6 tot stabiele tolerantiebedragen in de tijd. De overige methodieken kunnen tot stabiele uitkomsten leiden, indien zij over meerdere jaren worden gemiddeld. Dit laatste gaat echter ten koste van de eenvoud van toepassing (zie criterium $c$ ).

\section{b Mate waarin rekening wordt gehouden met bij- zondere omstandigheden}

Geen van de methodieken houdt impliciet rekening met bijzondere omstandigheden. Met behulp van een checklist kunnen deze omstandigheden in de specifieke situatie worden onderkend. De berekende tolerantie zal bij alle methodieken op basis van de beoordeling van deze omstandigheden eventueel moeten worden aangepast.

\section{c Eenvoudige toepasbaarheid}

Doordat gebruik gemaakt wordt van een range van mogelijke parameters kunnen de methodieken 1, 2 en 5 leiden tot verschillende uitkomsten in overeenkomstige situaties. Dit meerduidige karakter bemoeilijkt de praktische toepassing en de uniformiteit.

De overige methodieken zijn daarentegen relatief eenvoudig toepasbaar.

d Rekening houdend met de aard van de huishouding

Geen van de genoemde methodieken houdt expliciet rekening met de aard van de huishouding.

Uit bovenstaande evaluatie kan worden geconcludeerd dat de diverse methodieken kunnen leiden tot een grote variatie in tolerantiebedragen. Uit onderzoek dat onder accountants op de jaarlijkse bijeenkomst van het Institute of Chartered Accountants of Ontario (1977) werd gehouden bleek zelfs dat de door honderd geënquêteerden opgegeven tolerantiebedragen tot een factor 30 varieerden (Leslie p. 23). Ook hieruit blijkt dat er geen eenduidige opvatting bestaat omtrent de praktische invulling van het tolerantiebegrip.

\section{Een alternatieve benadering}

In deze paragraaf zullen wij nader ingaan op de wijze waarop wij hebben onderzocht in hoeverre een aanvaardbare methodiek is te ontwerpen voor het bepalen van de tolerantie in de jaarrekening.

Gedurende 1988 hebben wij een aantal accountants van Dijker en Doornbos benaderd, met het verzoek aan te geven wat in een aantal jaarrekeningen van Nederlandse ondernemingen de tolerantie bedroeg. Hierbij diende tevens te worden aangegeven welke overwegingen bij het vaststellen van de tolerantie een rol speelden.

Vooralsnog hebben wij ons uitsluitend op ondernemingen gericht, dat wil zeggen dat er geen nonprofit cliënten in het onderzoek zijn betrokken.

De door de accountants bepaalde tolerantiebedragen zijn met behulp van regressie-analyse 


\section{MAB}

gekoppeld aan enkele jaarrekeningcomponenten, waarvan bij ons de verwachting bestond dat deze een belangrijke invloed zouden kunnen hebben op het oordeel van de gebruiker. Bedoelde componenten zijn:

toegevoegde waarde (TW);

bedrijfsresultaat (BDR);

activa-totaal (AT);

eigen vermogen (EV).

De uitkomst van ons onderzoek is weer te geven door een formule met de volgende structuur:

Tolerantie in jaarrekening $=$

$\mid \beta_{\mathrm{o}}+\beta_{\mathrm{tw}}{ }^{*} \mathrm{TW}+\beta_{\mathrm{bdr}}{ }^{*} \mathrm{BDR}+\beta_{\mathrm{at}}{ }^{*} \mathrm{AT}+\beta_{\mathrm{ev}}{ }^{*} \mathrm{EV}$

De onafhankelijke variabelen (TW, BDR, AT, EV) correleerden voldoende met door de accountants geschatte tolerantiebedragen. Het bleek dat variabelen die verband houden met de winst- en verliesrekening (TW en BDR) een hogere verklarende waarde hebben dan variabelen die samenhangen met balansposten (AT en EV).

Alle variabelen hebben een positieve parameter $(\beta)$. Conform de eerder genoemde methodieken betekent dit dat naarmate de waarde van de variabelen toeneemt, ook de tolerantie zal toenemen. De uitkomst van de formule is de absolute waarde van de regressievergelijking, zodat negatieve uitkomsten uitgesloten zijn. Vanzelfsprekend is de weergegeven formule slechts een voorbeeld van een mogelijke regressievergelijking. Zo zou een onderzoek onder Angelsaksisch georiënteerde accountants kunnen leiden tot een formule waarin balansposten een hogere verklarende waarde bezitten. Omdat het onderzoek gebaseerd is op het oordeel van een kleine groep accountants, hebben wij ons beperkt tot het weergeven van de formule in algemene zin, zonder in te gaan op de waarden van de parameters. Het onderzoek is echter op eenvoudige wijze uit te breiden en te valideren.

Een verschil tussen de eerder genoemde methodieken (met uitzondering van methodiek 5) en de regressie-formule is dat de laatste de tolerantie berekent aan de hand van meerdere componen- ten uit de jaarrekening. Het gebruik van meerdere componenten schept zowel een waarborg tegen al te grote schommelingen van de tolerantie in de tijd, als tegen verschillen in tolerantie bij overigens vergelijkbare ondernemingen.

Tenslotte merken wij op dat regressie-analyse vanzelfsprekend slechts een van de methoden is om structuur aan te brengen in het kwantificeren van het tolerantiebegrip. Een ons inziens aanvaardbaar alternatief is het ontwikkelen van een expertsysteem, waarin de kennis van meerdere accountants is verzameld. Een dergelijk systeem heeft als voordeel dat ook eventuele kwalitatieve aspecten van het bepalen van de tolerantie in het model geïntegreerd kunnen worden. Dergelijke aspecten vormen een mogelijke beperking van de hanteerbaarheid van op eenvoudige rekenregels berustende methodieken.

Te denken valt in dit verband bijvoorbeeld aan ondernemingen met specifieke kenmerken en aan expliciet door gebruikers geformuleerde nauwkeurigheidseisen.

\section{Toerekening aan de posten van de jaarrekening}

In deze paragraaf willen wij enkele algemene opmerkingen plaatsen bij de wijze van toerekening van de tolerantie aan de posten van de jaarrekening.

Alle in dit artikel besproken methodieken berekenen een tolerantiebedrag voor de jaarrekening als geheel, waarna dit bedrag via verschillende technieken aan de diverse posten in de jaarrekening kan worden toegerekend. Deze toerekening is noodzakelijk omdat verondersteld kan worden dat de gebruiker zich in het algemeen zal richten op de getrouwheid van specifieke componenten. In NIVRA-geschrift 46 wordt uitgebreid ingegaan op de technieken om de tolerantie over de posten van de jaarrekening te verdelen.

Een ons inziens belangrijk probleem dat zich hierbij voordoet hangt samen met het feit dat fouten in de jaarrekening slechts zelden op zich zelf staan. Het systeem van dubbel boekhouden brengt tenslotte met zich mee dat een afwijking in een bepaalde post van de jaarrekening gepaard 


\section{MAB}

gaat met een even grote afwijking in een of meer andere posten. Dit kan gevolgen hebben voor het toerekenen van de tolerantie aan de posten alsmede voor de evaluatie van de uitkomsten van de controle. In veel gevallen zullen elkaar compenserende fouten in balansposten van minder betekenis zijn dan fouten die invloed hebben op het resultaat. Een techniek die uitgaat van de 'tolerantie in de jaarrekening als geheel' kan met dit effect slechts zijdelings rekening houden, omdat met elkaar samenhangende fouten worden geaggregeerd.

Tevens dient bij de verdeling van de totale tolerantie over de componenten van de jaarrekening rekening te worden gehouden met de betekenis van afwijkingen die individuele posten van de jaarrekening kunnen hebben voor specifieke gebruikersgroepen. Geconcludeerd kan worden dat ook dit aspect niet in een algoritme is te vatten, maar in iedere situatie specifieke aandacht behoeft.

Zoals door ons reeds in paragraaf 3 is aangegeven, blijkt nog eens dat iedere methodiek die leidt tot een tolerantiebedrag, zodanig van opzet dient te zijn, dat ruimte wordt gelaten voor het vakkundig oordeelsvormingsproces.

\section{Tolerantie en fouten in de jaarrekening}

In deze paragraaf zullen wij enige aandacht besteden aan een ons inziens belangrijk probleem waarmee men bij het integreren van de eerder genoemde methodieken in de accountantscontrole geconfronteerd kan worden.

Globaal zijn in het controleproces drie fasen te onderscheiden, namelijk:

- de planning en voorbereiding,

- de uitvoering, en

- de evaluatie (waarbij de strekking van de verklaring wordt vastgesteld).

In de planningsfase zal door de accountant onder andere worden vastgesteld met welke tolerantie gecontroleerd dient te gaan worden. De uitvoeringsfase van de controle is er vooral op gericht om materiële fouten en/of omissies in de betreffende jaarrekening te onderkennen voor zover deze zijn veroorzaakt door foutieve berekeningen, foutieve coderingen, foutieve toerekening van perioderesultaten en dergelijke.

Voor zover dit soort fouten van betekenis zijn, zullen wij ze aanduiden als materiële 'harde fouten'. Het is vanzelfsprekend noodzakelijk dat de accountant aan het eind van de uitvoeringsfase exact weet welke zekere en meest waarschijnlijke 'harde fouten' geconstateerd zijn.

In de evaluatiefase van de controle wordt de accountant bij zijn oordeelsvorming omtrent de getrouwheid van de opgeleverde cijfers vaak geconfronteerd met afwegingen betreffende de aanvaardbaarheid van posten in de jaarrekening, die het karakter van schattingen hebben. Van Manen noemt dit in zijn artikel in het MAB van april 1989 (Accountantscontrole en schattingen) 'zachte posten'. In deze fase van de controle kan niet meer gesproken worden van de 'juistheid' van de gepresenteerde schattingen.

De geschatte posten kunnen in twee categorieen worden verdeeld (Leslie D. A.):

\section{Objectief geschatte posten}

Deze zijn op formules of andere criteria gebaseerd. De criteria worden afgeleid uit in het verleden opgedane ervaringen, zoals een percentage voor het bepalen van een dynamische voorziening. De accountant beoordeelt in dit geval de aanvaardbaarheid en de consistente toepassing van een in het verleden gehanteerde grondslag (norm). De uitkomst van de toepassing van deze grondslagen is bij het beoordelen van de geschatte post vervolgens een gegeven.

\section{Subjectief geschatte posten}

Deze geschatte posten zijn hoofdzakelijk gebaseerd op verwachtingen van het management, waarbij een objectieve standaard of norm, op basis waarvan de omvang van de post door de accountant kan worden beoordeeld, ontbreekt. Te denken valt hierbij aan een statische bepaling van voorzieningen. Als gevolg van het ontbreken van een norm zal de accountant moeten volstaan met het beoordelen van de aanvaardbaarheid van de schattingen en de hieraan ten grondslag liggende verwachtingen. 


\section{MAB}

De accountant kan dus in beide gevallen beoordelen of de geschatte posten op aanvaardbare wijze tot stand zijn gekomen. Verschil van mening tussen accountant en bedrijfsleiding omtrent de hoogte van de geschatte post, heeft betrekking op de aan de schatting ten grondslag liggende uitgangspunten. Fouten in de objectief geschatte posten rangschikken wij onder de harde fouten voor zover deze eenduidig te kwantificeren zijn (afwijking ten opzichte van een in het verleden bepaalde norm).

Daarnaast kan er verschil in opvatting bestaan tussen de accountant en de bedrijfsleiding omtrent de hoogte van subjectief geschatte posten en de aanvaardbaarheid van de grondslagen van de objectief geschatte posten. Hier kan van 'zachte fouten' gesproken worden. leerde gebruikelijke schattingsmethoden toepast, weinig aanleiding tot ernstige verwijten kunnen geven. Om deze reden zijn wij er met Van Manen voorstander van dat de aard en de overwegingen van de schattingen van zachte posten in de jaarrekening opgenomen worden, zodat de gebruiker hieromtrent geïnformeerd wordt.

Samenvattend kan worden gesteld dat de fouten in de jaarrekening na accountantscontrole bestaan uit de niet gecorrigeerde harde fouten en de onwaarschijnlijke elementen in de geschatte posten (zachte fouten). Bij het evalueren van de controle zal het verschil tussen de vooraf bepaalde tolerantie en opgetreden fouten in de jaarrekening moeten worden vastgesteld.

Een en ander is weergegeven in tabel 2.

Tabel 2: Evaluatie van opgetreden fouten

\begin{tabular}{llll}
\hline Jaarrekening & Tolerantie & Opgetreden & $\begin{array}{l}\text { Minimaal } \\
\text { te corrigeren }\end{array}$ \\
\hline Harde fouten & $\begin{array}{l}\text { vooraf bepaald } \\
\text { met behulp van methodiek } \\
(1)\end{array}$ & $\begin{array}{l}\text { tijdens controle } \\
\text { geconstateerd } \\
(2)\end{array}$ & \\
\hline Zachte fouten & $\begin{array}{l}\text { (2) (1) } \\
\text { redelijkheids- } \\
\text { oordeel (zone } \\
\text { of reasona- } \\
\text { bleness) } \\
\text { (3) }\end{array}$ & $\begin{array}{l}\text { onwaarschijnlijke } \\
\text { elementen } \\
(4)\end{array}$ & \\
\hline
\end{tabular}

Het tijdens de evaluatiefase aggregeren door de accountant van zachte met harde fouten is ons inziens niet juist. Zou men dit wel doen, dan worden de fouten in de jaarrekening met een nauwkeurigheid vastgesteld die vele malen groter is dan de nauwkeurigheid waarmee de schattingen tot stand zijn gekomen.

Een tweede overweging om zachte fouten niet op dezelfde wijze te evalueren als harde fouten, is het verschil in consequentie die deze mogelijk materiële afwijkingen kunnen hebben voor de gecontroleerde en de controleur. Met name subjectieve schattingen die achteraf onjuist blijken te zijn zullen over het algemeen, mits de accountant zijn overwegingen goed vastlegt en de gecontro-

\section{Afsluitende opmerkingen}

In dit artikel zijn wij ingegaan op het begrip tolerantie in de jaarrekening. Om de duidelijkheid voor de gebruiker van de jaarrekening te vergroten en de efficiency van de accountantscontrole te verhogen, verdient het naar onze mening aanbeveling gebruik te maken van een uniforme methodiek voor het bepalen van de tolerantie.

Een dergelijke methodiek dient rekening te houden met de omvang en de aard van de huishouding, en dient eenvoudig toepasbaar te zijn.

In de methodiek (zoals door ons in paragraaf 4 beschreven), die gebaseerd is op het vakkundige 
oordeel van accountants, wordt met bovengenoemde aspecten rekening gehouden.

In dit artikel is er naar gestreefd duidelijk te maken dat het tolerantiebegrip zich niet gemakkelijk in een uitsluitend kwantitatief model laat dwingen. Zo kan worden opgemerkt dat het bij de in paragraaf 2 besproken kwantitatieve benaderingen niet gaat om het beoordelen van fouten en/of omissies die betrekking hebben op de toelichting in de jaarrekening, of op de aan de jaarrekening te stellen formele eisen. Op de betekenis van dergelijke fouten en/of omissies zijn wij verder dan ook niet ingegaan.

Tevens hebben wij in dit verband aangegeven dat bij de verdeling van de totale tolerantie over de posten van de jaarrekening stilgestaan dient te worden bij de betekenis van afwijkingen die individuele posten van de jaarrekening kunnen hebben voor specifieke gebruikersgroepen. Tenslotte dient bij het bepalen van de tolerantie en het evalueren van de fouten onderscheid te worden gemaakt in harde en zachte fouten.

\section{Literatuur}

Carmichael D. R., M. Benis, Auditing Standards and Procedures Manual 1988, John Wiley \& Sons, New York.

Dijk, J. F. van, De betekenis van 'materiality' voor de accountantscontrole van de jaarrekening, Maandblad voor Accountancy en Bedrijfseconomie, januari/februari 1989, p. 6.

Elliott, R. K., J. R. Rogers, Relating statistical sampling to audit objectives, Journal of Accountancy, july 1972.

Elliott, R. K., c.s., Using materiality in audit planning, Journal of accountancy, maart 1983.

Leslie, D. A., Materiality, The Concept and its Application to Auditing, CICA 1985.

Manen, J. A. van, Accountantscontrole en schattingen, Maandblad voor Accountancy en Bedriffseconomie, april 1989, p. 103.

NIVRA geschriften nummer 46, Materialiteit bij de opstelling en de controle van de jaarrekening, Kluwer Bedrijfswetenschappen, Deventer, februari 1989.

Wallage, Ph., 1989, Accountantscontrole: (on)gestructureerd?, Maandblad voor Accountancy en Bedrijfseconomie, juni 1989, p. 213.
Ontwikkelingen in de accountantsfunctie

bij de lagere overheid

\section{J. Boeré}

\section{Inleiding}

De laatste jaren staat de overheid voor wat betreft het functioneren steeds meer in de belangstelling. Op zich zelf bezien niet zo verwonderlijk; immers wanneer de beschikbare middelen schaars worden, gaat men over die middelen zelf en de besteding daarvan nadenken.

De burgers zien vanzelfsprekende voorzieningen verdwijnen, zijn daar in de meeste gevallen niet gelukkig mee en vragen zich steeds kritischer af, wat er dan wèl met 'hun belastinggelden' gebeurt. De politici, tot nu toe meer gewend om alleen vooruit te denken, zien dat bepaalde doelstellingen uit hun programma bij gebrek aan middelen opeens niet meer kunnen worden gehaald; voor hen wordt, gegeven dit feit en de druk van de publieke opinie, het terugblikken nu ook van belang.

In het 'politiek bedrijf' komt naast het streven om doelstellingen te verwezenlijken, er 'politiek' doorheen te krijgen, ook de daadwerkelijke realisering ervan steeds meer in de belangstelling te staan. Doelmatig beheer, management van het ambtelijk apparaat, 'waar voor je geld' (value for money) zijn op dit moment bekende slogans in overheidsland. Het aansprakelijk stellen van politici voor mismanagement, niet alleen op rijksniveau, behoort de laatste tijd bepaald niet tot de

J. Boeré behaalde het accountantsexamen in 1969. Sinds 1 december 1989 werkzaam als algemeen directeur van het Energiebedrijf Gemeente Groningen. Tot voor kort voorzitter Vereniging van Directeuren van Provinciale en Gemeentelijke Accountantsdiensten (VDA). 